\title{
Urogynecology Section of the Polish Society of Gynecologists and Obstetricians guidelines on the management of stress urinary incontinence in women
}

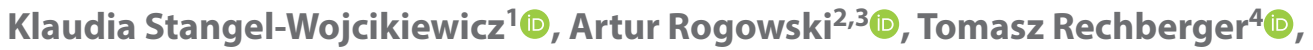 \\ Wlodzimierz Baranowski ${ }^{5}$, Magdalena E. Grzybowska ${ }^{6}{ }^{\infty}$, Tomasz Kluz ${ }^{7} \mathbb{C D}^{\circ}$

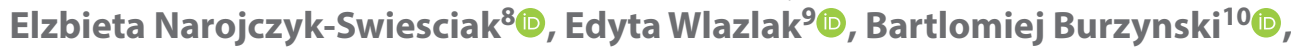 \\ Grzegorz Surkont ${ }^{9}$ (i) \\ ${ }^{1}$ Department of Gynecology and Oncology, Jagiellonian University Medical College, Cracow, Poland \\ ${ }^{2}$ Department of Gynecology, ,IInflancka" Specialist Hospital, Warsaw, Poland \\ ${ }^{3}$ Collegium Medicum, Cardinal Stefan Wyszynski University, Warsaw, Poland \\ ${ }^{4} / \mathrm{I}$ Department of Gynecology, Medical University of Lublin, Poland \\ ${ }^{5}$ Department of Gynecology, Gynecological Oncology, Military Medical Institute, Warsaw, Poland \\ ${ }^{6}$ Department of Gynecology, Gynecological Oncology and Gynecological Endocrinology, Medical University of Gdansk, Poland \\ ${ }^{7}$ Clinic of Gynecology and Obstetrics, Institute of Medical Science, College of Medical Science, University of Rzeszow, Poland \\ 8 II Department of Obstetrics and Gynecology, Centre of Postgraduate Medical Education, Bielanski Hospital Warsaw, Poland \\ ${ }^{9}$ Department of Operative Gynecology and Gynecological Oncology, I Department of Gynecology and Obstetrics, \\ Medical University of Lodz, Poland \\ ${ }^{10}$ Department of Rehabilitation, Faculty of Health Sciences in Katowice, Medical University of Silesia in Katowice, Poland
}

\begin{abstract}
Objectives: The aim was to present an interdisciplinary Guideline of the Urogynecology Section of the Polish Society of Gynecologists and Obstetricians (PSGO) for the management of stress urinary incontinence (SUI).

Material and methods: A review of the literature, including current international guidelines and earlier recommendations of the PSGO Urogynecology Section, about the treatment of SUI was conducted.

Results: Management of SUI is presented. Four lines of therapy were identified: line 1 - the so-called 'conservative treatment', which should always be attempted, regardless of SUI symptom severity; line 2 - surgical intervention; lines 3 and 4 - reoperations after unsuccessful surgeries from line 2 . The literature reports which provided supporting evidence for this Guideline, including the practical aspects, were discussed.

Conclusions: A systematic review of the guidelines and an analysis of SUI management were conducted. The need for an individualized approach was emphasized.

Key words: urinary incontinence, stress urinary incontinence, conservative treatment, physiotherapy, surgical treatment, midurethral sling, colposuspension
\end{abstract}

Ginekologia Polska 2021; 92, 11: 822-828 


\section{INTRODUCTION}

Stress urinary incontinence (SUI) is defined as involuntary leakage of urine on effort or exertion, or with coughing or sneezing [1, 2]. SUI affects a significant number of women and negatively impacts their quality of life. As many as $75 \%$ of older, $44-57 \%$ of middle-aged, and $25 \%$ of young women report symptoms of urinary incontinence [3].

\section{Objectives}

The aim of this publication was to develop a Guideline for the management of stress urinary incontinence, based on the available literature, expert knowledge, and everyday practice.

\section{MATERIAL AND METHODS}

In 2005, 2006 and 2010, the expert panel of the Polish Society of Gynecologists and Obstetricians (PSGO) developed guidelines for the diagnosis and treatment of urogynecologic conditions. The present publication is an update of those recommendations, based on the literature reports published between 2010 and 2019, as well as the recommendations of the American Urological Association, the International Urogynecology Association, the European Association of Urology, and the Canadian Urological Association [4].

The literature about the management of SUI, including the current international guidelines, was reviewed. Special attention has been paid to the level of evidence and degree of recommendation of the available data sources. If the literature source seemed insufficient, expert opinions and management protocols were included.

\section{GUIDELINES}

First-line treatment: non-surgical treatment

At the first stage of the treatment, it is important to inform the patient about the details of the management which aims to minimize the discomfort associated with urinary incontinence, i.e. the smell of urine, skin irritation due to prolonged exposure to urine, and the feeling of loss of control over one's body. The use of personal hygiene products such as pads and sanitary towels is recommended.

The choice of non-surgical methods should be tailored to the individual needs and symptoms of the patient, and her ability to comply with the therapy. Patient motivation to introduce lifestyle changes and compliance positively affect treatment efficacy.

Among the methods of non-surgical treatment of SUI, the following should be considered:

1. treatment of concomitant diseases and drug modification;

2. lifestyle modifications;

3. treatment and prevention of recurrent urinary tract infections;
4. physiotherapy;

5. supportive devices: pessaries, vaginal tampons;

6. pharmacotherapy.

\section{Second-line treatment: first-line surgical interventions}

If the conservative therapy proves ineffective or the physical examination reveals high-grade urinary incontinence, with unfavorable prognosis after conservative management, second-line treatment, i.e., surgery, is recommended.

A. MUS (midurethral sling) procedure, during which the sling is placed in the middle part of the urethra, or retropubic colposuspension (Burch) are the most common first-line surgical treatments.

B. If the tape surgery proves unsuccessful, implant removal and the insertion of a new tape is recommended. Some specialists suggest to perform Burch colposuspension in such cases. In patients with persistent SUI symptoms after Burch colposuspension, MUS may be considered [5-7].

\section{Third-line treatment: second-line surgical interventions}

If first-line surgical treatment (usually after both surgeries) proved ineffective or in selected cases, the following are used as second-line surgery:

a) urethral bulking agents

b) autologous pubovaginal sling

\section{Fourth-line treatment: third-line surgical interventions}

If the first- and second-line surgical interventions prove ineffective, an artificial urethral sphincter and an adjustable compression device may be considered in selected cases.

\section{OVERVIEW OF THE RECOMMENDATIONS}

The literature offers a number of effective therapies for SUI, including various types of non-surgical and surgical treatments. Conservative management should be the first stage of SUI therapy [8].

\section{Non-surgical treatment}

Conservative management should be attempted in many patients, even if surgical treatment had already been planned. The effectiveness of non-surgical treatment is typically evaluated after 8 to 12 weeks.

The use of protective materials (high absorbency pads and sanitary towels, intravesical catheters which allow for external urine collection) can improve the short- and long-term patient comfort [9]. Appropriate sanitary products are well-tolerated, and women of all ages use them willingly. Product diversity enables the users to adjust the size 
as well as the following features: absorption, odor control, anti-allergic properties, etc. (LE 1b).

1. Drug modification may reduce the symptoms of SUI in patients treated for concomitant diseases, e.g., metabolic syndrome, cardiovascular diseases, respiratory system diseases, chronic renal failure, degenerative syndromes, including multiple sclerosis, mental diseases, and depression [10].

2. Educating the patient about lifestyle modifications often results in significant improvement. It also allows the patients to better understand the nature of the disease and, consequently, to treat it more effectively.

a) Consumption of fluids containing caffeine or theine (coffee, tea, carbonated drinks) and alcohol beverages

The literature offers no evidence of a linear association between caffeine intake (equivalent to one cup of coffee/day) and the prevalence and severity of urinary incontinence. Only reduction of caffeine intake combined with behavioral therapy was demonstrated to reduce urgency, but it did not reduce urinary incontinence as compared to behavioral therapy alone [11]. Therefore, lower caffeine intake does not reduce symptoms of urinary incontinence (LE2). It is recommended to reduce fluid intake (including fluids which increase diuresis) two hours before bedtime, especially in patients with early morning and night urinary incontinence.

b) Treatment of overweight and obesity

Overweight and obesity are confirmed risk factors for the development of urinary incontinence. SUI is believed to occur even 4.2-fold more often in obese women as compared to their normal body weight peers [12]. The loss of at least $5 \%$ of the initial weight is recommended. According to NICE, weight reduction should be recommended to women with the BMI of $>30 \mathrm{~kg} / \mathrm{m}^{2}[13,14]$. Even a slight reduction of the body weight can improve urinary continence in overweight and obese women [15] (LE 1a).

c) Treatment of constipation

Constipation is a common occurrence in patients with urinary incontinence. According to an observational study in women with urinary incontinence, women with POP, and controls, history of constipation was associated with both, pelvic organ prolapse and urinary incontinence [16]. However, no evidence supports the alleviation of SUI symptoms after reduction of constipation (LE 4).

d) Physical activity

Regular physical activity can positively affect pelvic floor muscles and reduce urinary incontinence episodes. Resistance training with additional load, high-intensity jumping, e.g., trampolining, as well as high-intensity running should be excluded. Various studies demonstrated elevated risk for developing SUI in active women, especially sportswomen.
There is evidence that women who do sports experience urinary incontinence later in life (LE 3 recommendation) $[17,18]$. Nevertheless, proper body weight and higher mobility when accessing the toilet are undeniable benefits of engaging in regular physical activity.

e) Smoking cessation

No relationship between smoking cessation and improved urine control has been demonstrated. However, smoking-associated cough may increase the intra-abdominal pressure and intensify the symptoms of urinary incontinence [19].

\section{f) Bladder training}

Controlled voiding, scheduled micturitions with gradually extended time intervals between voiding and correct urination habits are elements of bladder training. These techniques are typically used in the management of urgency urinary incontinence, but they also proved to be effective in SUI therapy [20].

3. Comprehensive diagnosis, treatment and prevention of urinary tract infections are important elements of managing patients with lower urinary tract symptoms. 4. Physiotherapy.

The most common physiotherapeutic methods used in the management of SUI in women include pelvic floor muscle training - PFMT (the so-called 'Kegel exercises'), biofeedback, ultrasonography feedback, EMG biofeedback, electrostimulation (superficial, vaginal), and pelvic floor manual therapy $[1,3,4,8,10,21]$. Incorrect physiotherapy may intensify urogynecological symptoms. Professional urogynecological physiotherapy should be initiated after the functional diagnosis. Its effectiveness depends on therapy duration and expert supervision over the therapeutic process [22]. PFMT includes different protocols and principles of this branch of physiotherapy. Separate guidelines for physiotherapeutic management of SUI in women have been presented elsewhere.

5. Supportive devices.

a) pessaries

Silicone pessaries (urethra and cerclage), with a thickening near the urethra, are usually recommended in SUI therapy. The desired effect is obtained when the thickening of the pessary supports the transition of the bladder and the urethra. The rim of the pessary must be sized so that it does not move and rests along the posterior wall of the vagina. If those pessaries prove ineffective, a cube-type pessary may be used. In such cases, the upper edge of the pessary should be placed under the urethra for support and urine control. A gynecological examination and adjustment of the material, durability, size and shape to the anatomic conditions are necessary to select the appropriate vaginal tampon or pessary. All the measures can be used periodically or remain the only form of conservative therapy (with 
the recommendation to change daily). In SUI therapy, the pessaries may be used during the day or whenever needed (LE 2a) [23-25].

b) vaginal tampons

Tampons made of special, flexible, and delicate medical material - PVA (vinyl polymer-polyvinyl alcohol) in the shape of a cylinder or a cube, are used in SUI therapy. The tampon is inserted under the urethra for support. It is recommended to use vaginal tampons only when necessary, which might mean only during sport activities or dancing for some patients, or throughout the day for others [25].

6. Pharmacotherapy of SUI.

Duloxetine, which inhibits the presynaptic re-uptake of serotonin (5-HT) and norepinephrine (NE), can be used in SUI therapy. A meta-analysis of four randomized, placebo-controlled clinical trials reported to the European Medicines Agency, demonstrated that duloxetine was more effective than placebo as far as the rates of weekly incontinence episodes were concerned [26]. Level LE 1a recommendation for duloxetine has been reported by the experts from the European Association of Urology, whereas in the USA, the FDA suspended the registration of this drug for SUI therapy [27]. Duloxetine is not registered for the treatment of SUI in Poland ('off label' use).

A review of the Cochrane database and the available literature indicated improved continence control in a short-term evaluation for vaginal estrogen use (LE 1a). The method of application is easy and safe for the patient. The degree of absorption and of systemic activity is so low that it can be used for short periods even in women after breast cancer treatment. The optimal duration of the therapy has not been determined and should be adjusted to the individual needs of the patient [28-30].

Systemic estrogen-progestogen replacement therapy may intensify the symptoms of urinary incontinence as compared to placebo [31].

\section{Second-line treatment: first-line surgery}

First-line surgical treatment of SUI includes: midurethral sling, during which the sling is placed in the middle part of the urethra, or retropubic colposuspension (Burch).

The choice of the procedure should be tailored to the individual needs of the patient, based on the symptoms and diagnostic results, as well as the expert knowledge and surgical experience of the physician. The scope of preoperative diagnostics depends on the symptoms, findings of the clinical examination and the additional tests, the experience of the physician and common practice in a given medical center. It is necessary to evaluate pelvic organ prolapse and the possible treatment methods before or during SUI surgery $[32,33]$. These issues have been discussed elsewhere, in the guideline for the surgical management of POP.

\section{MUS}

Currently, sling implantation under the middle part of the urethra is based on the use of macroporous tape (type 1 according to Amid's Classification) [34-37]. The tape parameters allow to significantly reduce the risk of exposure as compared to multifilament and microporous materials (higher risk of infection). With the advancements in this area, new materials will likely be used in the future. The method of sling implantation has been modified: the tape can be inserted from the suprapubic side down to underneath of the urethra (rarely used) or passed through the retropubic or the obturator space [38]. Some studies indicated the possibility of improved outcomes of SUI therapy after MUS surgery if the procedure is individualized using pelvic floor sonography (PFS). The choice of the implantation site is determined by urethral length and mobility and the type of sling [39-43].

\section{Retropubic colposuspension}

Colposuspension is usually performed in patients with paravaginal lateral defect and excessive mobility of the bladder neck, which causes SUI. Colposuspension may be performed in patients after MUS. MUS implantation is also often recommended after unsuccessful colposuspension $[7,44]$.

Colposuspension is associated with the rate of urinary incontinence correction ranging from $85-90 \%$ for the follow-up (FU) of 1-5 years after surgery to $70 \%$ for $\mathrm{FU}$ of $>5$ years. A comparison of colposuspension and MUS revealed no differences in the subjective or objective efficacy of SUI therapy, regardless of the time factor $[45,46]$ (LE 1a). Likewise, studies comparing the results of MUS from the retropubic versus obturator access ( $1-5$ years $F U$ and $>5$ years FU), found no differences in the subjective recovery rate (LE 1a). FU of $>5$ years showed the recovery rate of $51-88 \%$ for the retropubic and $43-92 \%$ for the obturator access [47]. The obturator access was associated with more frequent groin pain (6.4\% vs $0.6 \%$ ), while the retropubic access with a higher rate of bladder perforations ( $4.5 \%$ vs $0.6 \%$ ), difficulty passing urine, and organ and vessel injury (LE 1a).

\section{Third-line treatment: second-line surgery}

a) urethral bulking agents

The procedures which 'seal' the urethra consist in the administration of bulking agents, submucosally delivered via the transurethral or transvaginal route, which reduces the urethral lumen. The agents are typically injected into the submucosa surrounding the bladder neck or mid-urethra [48].

Due to the variety of the available bulking agents and lack of long-term observations, it is challenging to present unequivocal guidelines for their use in SUI therapy. Only 
short-term observations demonstrated improved urine control (1b) [49]. Therefore, bulking agent injection, despite being minimally invasive, should be treated as an alternative procedure for SUI: in the next stage of treatment, in patients with systemic diseases who do not want to undergo the classic procedures (2a) [50].

b) Autologous fascial sling, pubovaginal sling, bladder neck slings

This procedure uses a piece of the fascial tissue which stabilizes the urethra on the vaginal side. The most used sling is the autologous fascial sling, originating from the rectus sheath or the fascia lata of the thigh. It is not recommended as first-line treatment and should be used only in case of recurrent urinary incontinence after earlier procedures proved ineffective, in patients with internal sphincter deficiency, after prior radiotherapy, MUS failure, and after urethral injury. A comparison with MUS synthetic sling revealed that the procedures have similar efficacy [51]. Nevertheless, MUS seems to be more beneficial considering the increased risk for postoperative urination disorders, abnormal wound healing, and procedure duration which are associated with autologous slings.

\section{Fourth-line treatment: third-line surgical} treatment: artificial urinary sphincter (AUS) and adjustable compression therapy (ACT)

Implantation of an artificial urethral sphincter involves transabdominal insertion of a system which replaces the normal functions of a urethral sphincter. It is the final solution for patients with no urine control and after other surgical procedures proved unsuccessful (LE3) [52].

\section{Future course: regenerative medicine}

Autologous muscle-derived stem cells obtained by skeletal muscle biopsy and injected into the area of the urethral sphincter were shown to be effective in Phase I/II trials [53-55]. Randomized phase III trials (Clinicaltrials. gov Identifier: NCT01893138) are currently in progress. The proclaimed mechanism of action consists in promoting tissue remodeling by in situ secretion of growth factors and cytokines, which helps to restore the sphincter structure and its function [56] (LE 4).

\section{SUMMARY}

The implementation of targeted therapeutic management of SUI must be preceded by a thorough diagnostic process. Details about patient eligibility and correct qualification will allow to choose the optimal treatment and obtain urine control.

Surgical intervention (tailored to the individual needs of the patient) should be considered only after conserva- tive treatment and personal hygiene measures have been exhausted and SUI persists.

Importantly, guidelines are only an indication for the specialist treatment and will not replace clinical knowledge when making individualized therapeutic decisions, which in some cases may prompt the experts to deviate from the recommendations.

\section{Conflict of interest}

All authors declare no conflict of interest.

\section{REFERENCES}

1. Haylen BT, de Ridder D, Freeman RM, et al. International Urogynecological Association, International Continence Society. An International Urogynecological Association (IUGA)/International Continence Society (ICS) joint report on the terminology for female pelvic floor dysfunction. Neurourol Urodyn. 2010; 29(1): 4-20, doi: 10.1002/nau.20798, indexed in Pubmed: 19941278.

2. WlaźlakE, Surkont G, Shek KaL, et al. Can we predict urinary stress incontinence by using demographic, clinical, imaging and urodynamic data? Eur J Obstet Gynecol Reprod Biol. 2015; 193: 114-117, doi: 10.1016/j. ejogrb.2015.07.012, indexed in Pubmed: 26291686.

3. Bettez M, Tu LeM, Carlson K, et al. 2012 update: guidelines for adult urinary incontinence collaborative consensus document for the canadian urological association. Can Urol Assoc J. 2012; 6(5): 354-363, doi: 10.5489/cuaj.12248, indexed in Pubmed: 23093627.

4. Nambiar AK, Bosch R, Cruz F, et al. Asociación Europea de Urología, European Association of Urology. EAU guidelines on assessment and nonsurgical management of urinary incontinence. Eur Urol. 2012;62(6): 1130-1142, doi: 10.1016/j.eururo.2012.08.047, indexed in Pubmed: 22985745.

5. Fabian G, Kociszewski J, Kuszka A, et al. Vaginal excision of the sub-urethral sling: analysis of indications, safety and outcome. Arch Med Sci. 2015; 11(5): 982-982, doi: 10.5114/aoms.2014.42305, indexed in Pubmed: 26528340.

6. Giarenis I, Mastoroudes $\mathrm{H}, \mathrm{Cardozo} \mathrm{L}$, et al. What do we do when a midurethral tape fails? Rediscovery of open colposuspension as a salvage continence operation. International Urogynecology Journal. 2012; 23(8): 1117-1122, doi: 10.1007/s00192-012-1720-4.

7. Surkont G, Wlaźlak E, Petri E, et al. Standardized modified colposuspension--mid-term results of prospective studies in one centre. Ann Agric Environ Med. 2015; 22(2): 293-296, doi: 10.5604/12321966.1152082, indexed in Pubmed: 26094526.

8. Wein AJ. Committee Opinion No. 603: Evaluation of uncomplicated stress urinary incontinence in women before surgical treatment. Obstet Gynecol. 2014; 123(6): 1403-1407, doi: 10.1097/01. AOG.0000450759.34453.31, indexed in Pubmed: 24848922.

9. Teunissen TAM, Lagro-Janssen ALM. Sex differences in the use of absorbent (incontinence) pads in independently living elderly people: do men receive less care? Int J Clin Pract. 2009; 63(6): 869-873, doi: 10.1111/j.17 42-1241.2008.01975.x, indexed in Pubmed: 19490196.

10. Sarma AV, Kanaya A, Nyberg LM, et al. Diabetes Control and Complications Trial/Epidemiology of Diabetes Interventions and Complications Research Group. Risk factors for urinary incontinence among women with type 1 diabetes: findings from the epidemiology of diabetes interventions and complications study. Urology. 2009; 73(6): 1203-1209, doi: 10.1016/j.urology.2008.11.009, indexed in Pubmed: 19362350.

11. Bryant CM, Dowell CJ, Fairbrother G. Caffeine reduction education to improve urinary symptoms. Br J Nurs. 2002; 11(8): 560-565, doi: 10.12968/bjon.2002.11.8.10165, indexed in Pubmed: 11979209.

12. Fuselier A, Hanberry J, Margaret Lovin J, et al. Obesity and stress urinary incontinence: impact on pathophysiology and treatment. Curr Urol Rep. 2018; 19(1): 10, doi: 10.1007/s11934-018-0762-7, indexed in Pubmed: 29468457.

13. National Collaborating Centre for Women's and Children's Health (UK). Urinary Incontinence in Women: The Management of Urinary Incontinence in Women. London: Royal College of Obstetricians and Gynecologists (UK); 2013.

14. Nambiar AK, Bosch R, Cruz F, et al. Asociación Europea de Urología, European Association of Urology. EAU guidelines on assessment and nonsurgi- 
cal management of urinary incontinence. Eur Urol. 2012;62(6): 1130-1142, doi: 10.1016/j.eururo.2012.08.047, indexed in Pubmed: 22985745.

15. Whitcomb EL, Subak LL. Effect of weight loss on urinary incontinence in women. Open Access J Urol. 2011; 3: 123-132, doi: 10.2147/OAJU. S21091, indexed in Pubmed: 24198645.

16. Kaplan SA, Dmochowski R, Cash BD, et al. Systematic review of the relationship between bladder and bowel function: implications for patient management. Int J Clin Pract. 2013; 67(3): 205-216, doi: 10.1111/ijcp.12028, indexed in Pubmed: 23409689.

17. Carvalhais A, Natal Jorge R, Bø K. Performing high-level sport is strongly associated with urinary incontinence in elite athletes: a comparative study of 372 elite female athletes and 372 controls. Br J Sports Med. 2018; 52(24): 1586-1590, doi: 10.1136/bjsports-2017-097587, indexed in Pubmed: 28642223.

18. Nygaard IE. Does prolonged high-impact activity contribute to later urinary incontinence? A retrospective cohort study of female Olympians. Obstet Gynecol. 1997; 90(5): 718-722, doi: 10.1016/S00297844(97)00436-5, indexed in Pubmed: 9351751.

19. Hannestad YS, Rortveit G, Daltveit AK, et al. Are smoking and other lifestyle factors associated with female urinary incontinence? The Norwegian EPINCONT Study. BJOG. 2003; 110(3): 247-254, indexed in Pubmed: 12628262.

20. Fantl JA, Wyman JF, Harkins SW, et al. Bladder training in the management of lower urinary tract dysfunction in women. A review. J Am Geriatr Soc. 1990; 38(3): 329-332, doi: 10.1111/j.1532-5415.1990.tb03514.x, indexed in Pubmed: 2179377.

21. Marques $A$, Stothers $L$, Macnab A. The status of pelvic floor muscle training for women. Can Urol Assoc J. 2010; 4(6): 419-424, doi: 10.5489/cuaj.10026, indexed in Pubmed: 21191506.

22. Dumoulin C, Cacciari LP, Hay-Smith EJ. Pelvic floor muscle training versus no treatment, or inactive control treatments, for urinary incontinence in women. Cochrane Database Syst Rev. 2018; 10: CD005654, doi: 10.1002/14651858.CD005654.pub4, indexed in Pubmed: 30288727.

23. Cundiff GW, Weidner AC, Visco AG, et al. A survey of pessary use by members of the American urogynecologic society. Obstet Gynecol. 2000; 95(6 Pt 1): 931-935, doi: 10.1016/s0029-7844(00)00788-2, indexed in Pubmed: 10831995.

24. Donnelly MJ, Powell-Morgan S, Olsen AL, et al. Vaginal pessaries for the management of stress and mixed urinary incontinence. Int Urogynecol J Pelvic Floor Dysfunct. 2004; 15(5): 302-307, doi: 10.1007/s00192-0041163-7, indexed in Pubmed: 15300365.

25. Wlaźlak E, Krzycka M, Surkont G. Wysiłkowe nietrzymanie moczu-leczenie zachowawcze, pessaroterapia. In: Baranowski, W, Rogowski A. ed. Uroginekologia. Medical Tribune : 254-265.

26. Maund E, Guski LS, Gøtzsche PC. Considering benefits and harms of duloxetine for treatment of stress urinary incontinence: a meta-analysis of clinical study reports. CMAJ. 2017; 189(5): E194-E203, doi: 10.1503/cmaj.151104, indexed in Pubmed: 28246265.

27. Historical information on duloxetine hydrochloride (marketed as Cymbalta). Silver Spring (MD): Food and Drug Administration (US); 2013. www.fda.gov/drugs/drugsafety/postmarketdrugsafetyinformationforpatientsandproviders/ucm114970htm (2016 May 30).

28. Cody JD, Jacobs ML, Richardson K, et al. Oestrogen therapy for urinary incontinence in post-menopausal women. Cochrane Database Syst Rev. 2012; 10: CD001405, doi: 10.1002/14651858.CD001405.pub3, indexed in Pubmed: 23076892.

29. Robinson D, Cardozo L. Estrogens and the lower urinary tract. Neurourol Urodyn. 2011 ; 30(5): 754-757, doi: 10.1002/nau.21106, indexed in Pubmed: 21661025.

30. Donders GGG, Ruban K, Bellen G, et al. Pharmacotherapy for the treatment of vaginal atrophy. Expert Opin Pharmacother. 2019; 20(7): 821-835, doi: 10.1080/14656566.2019.1574752, indexed in Pubmed: 30897020.

31. Hendrix SL, Cochrane BB, Nygaard IE, et al. Effects of estrogen with and without progestin on urinary incontinence. JAMA. 2005; 293(8): 935-948, doi: 10.1001/jama.293.8.935, indexed in Pubmed: 15728164.

32. Lemos N, Korte JE, Iskander M, et al. Center-by-center results of a multicenter prospective trial to determine the inter-observer correlation of the simplified POP-Q in describing pelvic organ prolapse. Int Urogynecol J. 2012; 23(5): 579-584, doi: 10.1007/s00192-011-1593-y, indexed in Pubmed: 22083515.

33. KluzT, WlaźlakE, Surkont G. Transvaginal six-arm mesh OPUR in women with apical pelvic organ prolapse - analysis of short-term results, pelvic floor ultrasound evaluation. Ginekol Pol. 2017; 88(6): 302-306, doi: 10.5603/GP.a2017.0057, indexed in Pubmed: 28727128.

34. Amid PK. Classification of biomaterials and their related complications in abdominal wall hernia surgery. Hernia. 1997; 1(1): 15-21, doi: 10.1007/bf02426382.

35. Klinge $U$, Klosterhalfen B. Modified classification of surgical meshes for hernia repair based on the analyses of 1,000 explanted meshes. Hernia. 2012; 16(3): 251-258, doi: 10.1007/s10029-012-0913-6, indexed in Pubmed: 22562353.

36. Surkont G, Wlaźlak E, Suzin J. Long-term risk of complications after mid-urethral sling IVS implantation. Ann Agric Environ Med. 2015; 22(1): 163-166, doi: 10.5604/12321966.1141388, indexed in Pubmed: 25780848.

37. Kowalik CG, Dmochowski RR, De EJB. Surgery for female SUI: The $\mathrm{ICl}$ algorithm. Neurourol Urodyn. 2019; 38 Suppl 4: S21-S27, doi: 10.1002/nau.23879, indexed in Pubmed: 31050030.

38. Delorme E. [Transobturator urethral suspension: mini-invasive procedure in the treatment of stress urinary incontinence in women]. Prog Urol. 2001; 11(6): 1306-1313.

39. Wlaźlak E, Viereck V, Kociszewski J, et al. Role of intrinsic sphincter deficiency with and without urethral hypomobility on the outcome of tape insertion. Neurourol Urodyn. 2017; 36(7): 1910-1916, doi: 10.1002/nau.23211, indexed in Pubmed: 28139863.

40. Wlaźlak E, Kluz T, Kociszewski J, et al. The analysis of repeatability and reproducibility of bladder neck mobility measurements obtained during pelvic floor sonography performed introitally with $2 \mathrm{D}$ transvaginal probe. Ginekol Pol. 2017; 88(7): 360-365, doi: 10.5603/GP.a2017.0068, indexed in Pubmed: 28819940.

41. Wlaźlak E, Kluz T, Surkont $G$, et al. Urethral funneling visualized during pelvic floor sonography - analysis of occurrence among urogynecological patients. Ginekol Pol. 2018; 89(2):55-61, doi: 10.5603/GP.a2018.0010, indexed in Pubmed: 29512808.

42. Kuszka A, Rautenberg O, WlaźlakE, et al. Do different vaginal tapes need different suburethral incisions? The one-half rule. Neurourol Urodyn. 2015; 34(8): 741-746.

43. Kociszewski J, Rautenberg O, Kuszka A, et al. Can we place tension-free vaginal tape where it should be? The one-third rule. Ultrasound Obstet Gynecol. 2012; 39(2): 210-214.

44. Surkont G, Wlaźlak E, Dunicz-Sokolowska A, et al. [The efficacy of SUI treatment with Burch colposuspension evaluated with use of ITT analysis]. Ginekol Pol. 2007; 78(5): 378-380, indexed in Pubmed: 17867329.

45. Oliveira LM, Dias MM, Martins SB, et al. Surgical treatment for stress urinary incontinence in women: A systematic review and meta-analysis. Rev Bras Ginecol Obstet. 2018; 40(8): 477-490, doi: 10.1055/s-00381667184, indexed in Pubmed: 30142667.

46. Asıcıoglu O, Gungorduk K, Besımoglu B, et al. A 5-year follow-up study comparing Burch colposuspension and transobturator tape for the surgical treatment of stress urinary incontinence. Int J Gynaecol Obstet. 2014; 125(1): 73-77, doi: 10.1016/j.ijgo.2013.09.026, indexed in Pubmed: 24412004

47. Ford AA, Rogerson L, Cody JD, et al. Mid-urethral sling operations for stress urinary incontinence in women. Cochrane Database Syst Rev. 2017; 7: CD006375, doi: 10.1002/14651858.CD006375.pub4, indexed in Pubmed: 28756647.

48. Kuhn A, Stadlmayr W, Lengsfeld D, et al. Where should bulking agents for female urodynamic stress incontinence be injected? Int Urogynecol J Pelvic Floor Dysfunct. 2008; 19(6): 817-821, doi: 10.1007/s00192-0070535-1, indexed in Pubmed: 18157642.

49. Hegde A, Smith AL, Aguilar VC, et al. Three-dimensional endovaginal ultrasound examination following injection of Macroplastique for stress urinary incontinence: outcomes based on location and periurethral distribution of the bulking agent. Int Urogynecol J. 2013; 24(7): 1151-1159, doi: 10.1007/s00192-012-1983-9, indexed in Pubmed: 23229417.

50. Leone Roberti Maggiore U, Bogani G, Meschia M, et al. Urethral bulking agents versus other surgical procedures for the treatment of female stress urinary incontinence: a systematic review and meta-analysis. Eur J Obstet Gynecol Reprod Biol. 2015; 189: 48-54, doi: 10.1016/j. ejogrb.2015.03.025, indexed in Pubmed: 25855326.

51. Mahdy A, Ghoniem GM. Autologous rectus fascia sling for treatment of stress urinary incontinence in women: $A$ review of the literature. Neurourol Urodyn. 2019; 38 Suppl 4: S51-S58, doi: 10.1002/nau.23878, indexed in Pubmed: 30525246.

52. Alonso Ro, Fes As, Fernandez Barranco L, et al. Four-year experience with the flowsecure artificial urinary sphincter. Problems and solution. Neurol Urodyn. 2011; 30: 250. 
53. Stangel-Wojcikiewicz K, Piwowar M, Jach R, et al. Quality of life assessment in female patients 2 and 4 years after muscle-derived cell transplants for stress urinary incontinence treatment. Ginekol Pol. 2016; 87(3): 183-189, doi: 10.17772/gp/61330, indexed in Pubmed: 27306126.

54. Stangel-Wojcikiewicz K, Jarocha D, Piwowar M, et al. Autologous muscle-derived cells for the treatment of female stress urinary incontinence: A 2-year follow-up of a polish investigation. Neurourology and
Urodynamics. 2013; 33(3): 324-330, doi: 10.1002/nau.22404, indexed in Pubmed: 23606303.

55. Stangel-Wójcikiewicz K. egenerative Medicine for the Treatment of Urinary Incontinence. Jagiellonian University Press

56. Peters KM, Dmochowski RR, Carr LK, et al. Autologous muscle derived cells for treatment of stress urinary incontinence in women. JUrol. 2014; 192(2): 469-476, doi: 10.1016/j.juro.2014.02.047, indexed in Pubmed: 24582537. 